\title{
Worldwide decline in tonal frequencies of blue whale songs
}

\author{
Mark A. McDonald ${ }^{1, *}$, John A. Hildebrand ${ }^{2}$, Sarah Mesnick ${ }^{3,4}$ \\ ${ }^{1}$ WhaleAcoustics, 11430 Rist Canyon Road, Bellvue, Colorado 80512, USA \\ ${ }^{2}$ Scripps Institution of Oceanography, University of California San Diego, La Jolla, California 92093-0205, USA \\ ${ }^{3}$ Southwest Fisheries Science Center, National Marine Fisheries Service, NOAA, La Jolla, California 92037, USA \\ ${ }^{4}$ Center for Marine Biodiversity and Conservation, Scripps Institution of Oceanography, \\ University of California San Diego, La Jolla, California 92093-0202, USA
}

\begin{abstract}
Blue whale Balaenoptera musculus songs can be divided into at least 10 types worldwide, each type retaining the same units and similar phrasing over decades, unlike humpback whale song which changes substantially from year to year. Historical acoustic recordings dating back as far as the 1960s were examined, measuring the tonal frequencies of 1000s of blue whale songs. Within a given year, individuals match the song frequency (related to 'pitch' in musical nomenclature) to within less than $3 \%$. The best documented song type, that observed offshore of California, USA, now is sung at a frequency $31 \%$ lower than it was in the 1960s. Data available for 7 of the world's 10 known song types show they are all shifting downward in frequency, though at different rates. Any behavioral, ecological, oceanographic or anthropogenic change hypothesis seeking to explain the observed shifts should account for the worldwide occurrence of a nearly linear downward shift in the tonal frequencies of blue whale song. Hypotheses examined consider sexual selection, increasing ocean noise, increasing whale body size post whaling, global warming, interference from other animal sounds and post whaling increases in abundance. None of the commonly suggested hypotheses were found to provide a full explanation; however, increasing population size post whaling provides an intriguing and testable hypothesis that recovery is altering the sexually selected tradeoff for singing males between song amplitude (the ability to be heard at a greater distance) and song frequency (the ability to produce songs of lower pitch).
\end{abstract}

KEY WORDS: Blue whale $\cdot$ Song $\cdot$ Sexual selection $\cdot$ Ambient noise $\cdot$ Recovery $\cdot$ Population growth rate $\cdot$ Abundance

\section{INTRODUCTION}

Blue whales Balaenoptera musculus are an Endangered species worldwide, having been commercially hunted until 1972 (Clapham et al. 1999, Branch et al. 2004). During the past several decades, blue whale abundance appears to be increasing in most if not all regions, although the data for most areas are sparse and uncertain (Reeves et al. 1998, Calambokidis \& Barlow 2004; see Branch et al. 2007 for a review of worldwide blue whale distribution and abundance).

Blue whales migrate over large distances and produce songs throughout the year, at their tropical breeding grounds, during migration, and on their feeding grounds (Stafford et al. 1999, Širovic et al. 2004). The function of whale song, even the better-studied song of the humpback whale Megaptera novaeangliae, remains unexplained (Darling et al. 2006). Limited observations of singing blue whales suggest usage patterns different from those of humpback whale song and are even more difficult to explain (Oleson et al. 2007). All singers for which sex has been determined have been males, although both sexes produce non-song calls (Oleson et al. 2007). Singers have always been found to be traveling at relatively high speed, whereas non-song calls are commonly produced by milling or feeding blue whales (Ole- 
son et al. 2007). Blue whale song has a distinctive character and can be classified into at least 10 geographically distinct song types worldwide; McDonald et al. (2006a) describe 9 types, and recent recordings from near South Georgia Island show an additional type.

McDonald et al. (2006a) argued the value of division of blue whale populations based on the geographical distribution of each of the 9 song types, although the relationship between these populations and the current blue whale subspecies remains an area of confusion (Reilly et al. 2009). Genetic studies of blue whales have not yet resolved the many questions with regard to subspecies and population designations (LeDuc et al. 2007), and questions regarding the relationship of subspecies to song type have been discussed in recent studies (Samaran et al. 2008). The song types are stable over 10s of years in terms of the number of units, the character of the units and the phrasing, but not the frequency (related to pitch in music) of the song units. The presence of this frequency shift first became apparent to the authors of the present paper when developing automated blue whale song detectors as used in Burtenshaw et al. (2004). The detector had to be shifted lower in frequency each year to match the song produced at that time.

Technological advancements in automated long-term recording systems are increasing the importance of acoustic recordings as a passive monitoring tool for whale populations (Mellinger et al. 2007). Acoustic monitoring provides a complementary approach to conventional visual line transect surveys. Long-term acoustic recordings covering much of the world's oceans are becoming freely available from a variety of sources, such as the nuclear test monitoring network. What is needed now is development of the methods and understanding in order to use these acoustic data to improve our knowledge of blue whale migration patterns, population structure, abundance and behavior.

\section{MATERIALS AND METHODS}

Spanning the last 45 years, blue whale calls have been documented by underwater hydrophones deployed for both whale research and military use, by seafloor seismometers studying regional earthquakes, and more recently by dedicated whale acoustic recording packages. See Supplement 1 available at www.int-res.com/articles/suppl/n009p013_app.pdf for details of recording dates, locations, number of songs measured, measurement confidence intervals and the locations of archived recordings. Recordings from published reports, archival data, and from on-going projects to monitor blue whales worldwide were examined. When multiple songs from multiple animals were measured, the standard deviations (SD) and $95 \%$ confidence intervals as well as mean frequencies of song units were computed.

Songs separated substantially by time and/or distance (more than $24 \mathrm{~h}$ or about $100 \mathrm{~km}$, depending on acoustic propagation), are considered separate encounters. Statistical arguments regarding the likelihood of separate encounters being from different individuals based on travel speeds from tag data, time between encounters, population abundance, detection range and geographic range are not developed here, as individual status is not a critical assumption to the focus of this study. The whale encounter category is useful, nonetheless, in allowing a measure of frequency change within an individual song sequence versus other song sequences from different encounters within the same region and year.

In regions outside the eastern North Pacific, early raw acoustic recordings were rarely available and the data points have been measured from published spectrograms or waveforms and from published descriptions of the dominant frequency. In some instances, only a single song was available. Archival data from the 1960s and 1970s used analog tape recordings, whereas more recent data are based on digital recordings. Analog tape recordings were calibrated using pilot tones included on the tape, compensating for slight differences in tape speed. Frequency corrections for analog tape speed variance were on the order of a few percent.

Choice of frequency measurement points is illustrated in Fig. 1. Taking the eastern North Pacific song as an example, the first unit of the song is pulsed and lasts for about $20 \mathrm{~s}$, with a fundamental frequency of about $16 \mathrm{~Hz}$ and overtones at 5 additional frequencies. It is difficult to precisely measure the frequency of pulsive sounds, thus these types of sounds are not analyzed. The second unit of the song is nearly tonal and lasts for about $20 \mathrm{~s}$, with a series of harmonically related frequencies. The harmonic frequencies are precise integer multiples of the fundamental. The frequency of the tonal calls was measured with an accuracy of $0.1 \mathrm{~Hz}$ or better using the computer cursor on a spectrogram plot. For the eastern North Pacific song type the frequency of the 3rd harmonic tonal unit at its temporal mid-point was measured because greater precision is obtained at this integer multiple (Fig. 1).

Song frequency measurements occasionally require assumptions regarding which song phrase, if any, should be used, as most song types show variants in phrase order and occasional changes in character (Edds 1982, Mellinger \& Clark 2003). Each song component shifts proportionately, thus typically the frequency of only one (the clearest) is listed in Table S1. The exception in this study is the southeast Indian 

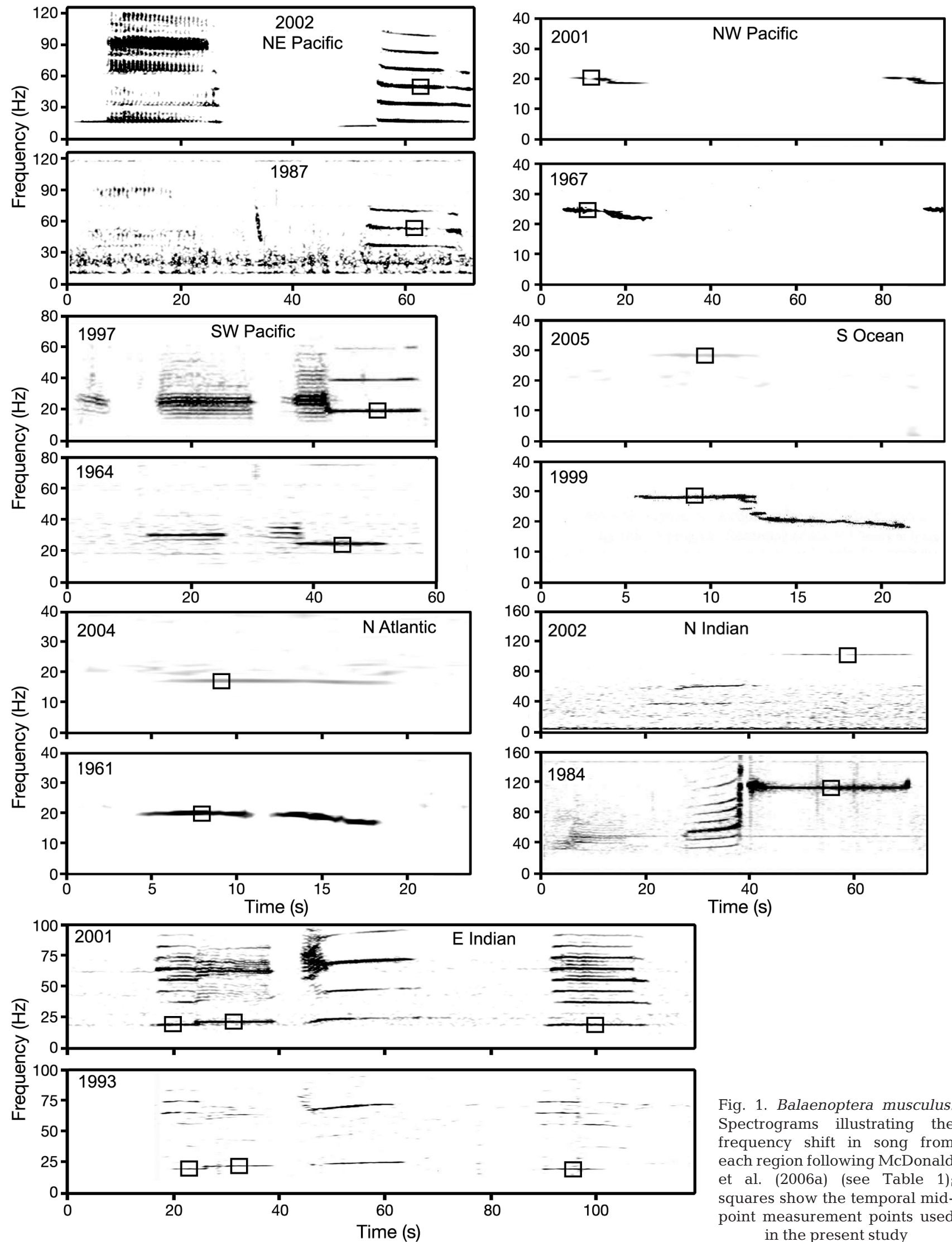

Fig. 1. Balaenoptera musculus. Spectrograms illustrating the frequency shift in song from each region following McDonald et al. (2006a) (see Table 1) squares show the temporal midpoint measurement points used in the present study 
Ocean song type, where additional averaging of the frequency shift using multiple song components was deemed appropriate, there being only 2 recordings available to this study.

\section{RESULTS}

The frequencies of blue whale song types for 7 of the 10 song types for which multiple years of data are available are all shifting downward (Table 1), although these frequencies are different for each song type. The best documented eastern North Pacific blue whale song exhibits a $0.4 \mathrm{~Hz} \mathrm{yr}^{-1}$ long-term linear downward frequency shift as measured at the third harmonic, with a downward trend that is surprisingly linear (correlation coefficient $r=-0.99$ ). In 1963 the song had a mean frequency at the third harmonic of $65.7 \mathrm{~Hz}$, whereas in 2008 the song had a frequency at the third harmonic of $45.5 \mathrm{~Hz}$ (Fig. 2). Equivalently, the fundamental frequency shifted from $21.9 \mathrm{~Hz}$ in 1963, to 15.2 Hz in 2008. In the eastern North Pacific, the tonal part of a blue whale's song today is $31 \%$ lower in frequency than it was $45 \mathrm{yr}$ ago.

The greatest relative change is observed in the 2 North Pacific song types and the least change in the south Indian Ocean song type (Fig. 3). The rate of downward frequency shift, expressed as a percentage, differs by as much as a factor of 2 between song types, but all units of each song type are shifting linearly such that a tonal at one-half the highest frequency will shift with a slope of one half that of the highest frequency. The southwest Indian Ocean and eastern South Pacific song type are not plotted because the available data are insufficient to measure any potential shift.

The most extensive dataset for blue whale song is from the eastern North Pacific, where the SD of this song type at the third harmonic within a whale encounter is 0.1 to $0.4 \mathrm{~Hz}$ with an average SD of $0.2 \mathrm{~Hz}$

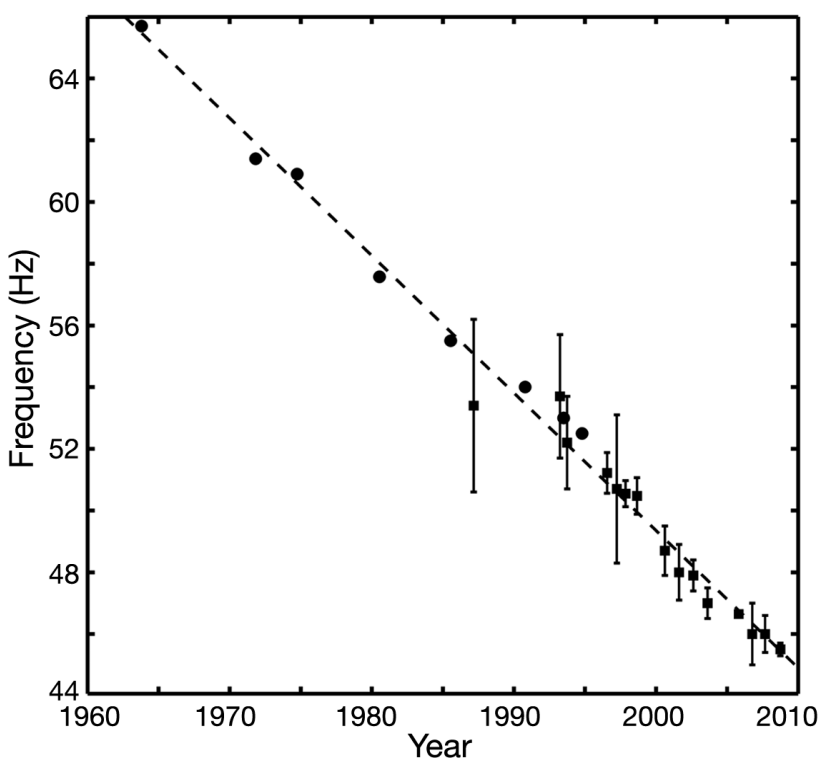

Fig. 2. Balaenoptera musculus. Third harmonic tonal frequencies for blue whale song in the northeast Pacific; $95 \%$ confidence limits are shown (squares with confidence bars). Dashed line is the least squares linear trend. Where no confidence limits are shown, there were insufficient data points to compute confidence intervals (circles). The larger confidence intervals are from published records for which raw data were not available and may represent different measurement methods. Raw data can be found in Table S1 (www.int-res.com/articles/suppl/n009p013_app.pdf)

Table 1. Balaenoptera musculus. Frequencies of blue whale song for the 7 song types for which multiple years of data are available. Theoretical source levels in $\mathrm{dB}$ re $1 \mu \mathrm{Pa} @ 1 \mathrm{~m}$ are calculated for the earliest and most recent data points for each song type and the $\mathrm{dB}$ per year change is calculated between these 2 points. The population density index is derived from the change in area ensonified at equal $\mathrm{dB}$ level assuming $17.5 \mathrm{log}$ (range) losses. The percent change in population density (den. \%) index over time is a proxy for population growth rate. Relative density index is referenced to the NE Pacific song type because this source level was used as an arbitrary reference point for the calculations. Potential size differences between populations would contribute second order corrections. Region labels follow McDonald et al. (2006a). Multiple measurements are given to improve precision where data were sparse and there were multiple tonal units in the song. Southern Ocean refers to the entire circumAntarctic region

\begin{tabular}{|c|c|c|c|c|c|c|}
\hline \multirow[t]{2}{*}{ Region } & \multicolumn{2}{|c|}{ Observed change } & \multirow[b]{2}{*}{$\begin{array}{c}\text { Change in } \\
\text { source level (dB) }\end{array}$} & \multicolumn{2}{|c|}{ - Model } & \multirow[b]{2}{*}{$\begin{array}{c}\text { Relative } \\
\text { density (\%) }\end{array}$} \\
\hline & Year range & Frequency & & $\begin{array}{l}\text { Chan } \\
\mathrm{dB}\end{array}$ & $\begin{array}{l}\text { e } \mathrm{yr}^{-1} \\
\text { den. } \%\end{array}$ & \\
\hline NE Pacific & 1963-2008 & 21.9 to 15.2 & $188.4-185.3$ & 0.067 & 1.8 & 100 \\
\hline SW Pacific & 1964-1998 & $30.8 / 25.3$ to $25.8 / 20.1$ & $190.7-188.8$ & 0.027 & 0.8 & 47 \\
\hline NW Pacific & $1968-2001$ & $25 / 23$ to $19.45 / 17.9$ & $187.1-184.9$ & 0.066 & 1.8 & 126 \\
\hline N Atlantic & $1959-2004$ & 23 to 17.6 & $196.3-193.9$ & 0.053 & 1.4 & 11 \\
\hline S Ocean & $1995-2005$ & 28.5 to 26.9 & $196.2-195.7$ & 0.050 & 1.3 & 7 \\
\hline N Indian Ocean & $1984-2002$ & 116 to 106 & $199.8-199.0$ & 0.044 & 1.2 & 3 \\
\hline SE Indian Ocean & $1993-2000$ & 19.5 to 19.0 & $186.9-186.6$ & 0.043 & 1.2 & 82 \\
\hline
\end{tabular}




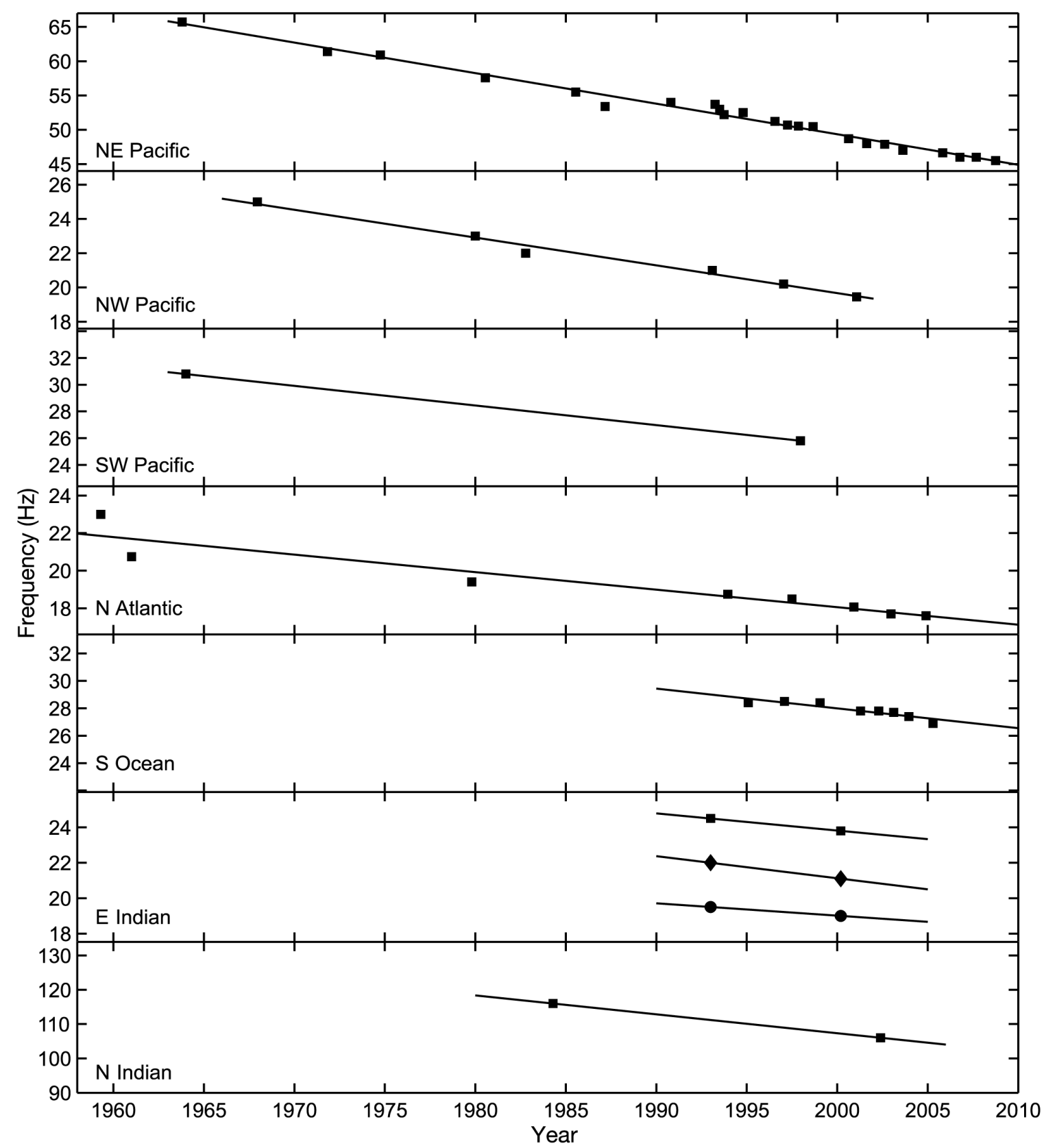

Fig. 3. Balaenoptera musculus. Frequency shift for 7 song types, labeled by region following McDonald et al. (2006a). Lines are least squares linear trends. The frequency scales were chosen to allow comparison of the slopes (e.g. a $100 \mathrm{~Hz}$ measurement point should have a frequency axis 5 times compressed relative to a $20 \mathrm{~Hz}$ point). The mean $95 \%$ confidence interval is $0.6 \mathrm{~Hz}$ and the individual values are in Supplement 1 (www.int-res.com/articles/suppl/n009p013_app.pdf). Circle and diamond symbols in the SE Indian region plot indicate additional tonal song units, added to improve the precision of this rate of change measurement.

Raw data can be found in Table S1

(typical $\mathrm{n}=10$ songs each from 10 separate encounters, similar deviations from one year to the next). Likewise, when calls from multiple encounters are averaged in a given year, the SD is less than $0.4 \mathrm{~Hz}$ from the mean frequency (typical $\mathrm{n}=1000$ calls within 1 season). Doppler frequency shifts due to swim speed can account for about $0.1 \mathrm{~Hz} \mathrm{SD}$ at the third harmonic.

\section{DISCUSSION}

Any hypothesis seeking to explain the observed frequency shifts should account for long-term change, almost worldwide occurrence, and a relatively linear shift. First we discuss cultural conformity and why blue whales may synchronize their songs in frequency dur- 
ing a given season. Next, we review a list of hypotheses seeking to explain the global pattern and our conclusions regarding the validity or promise of each.

\section{Cultural conformity and directional synchrony}

When new behavioral variants spread rapidly through a population over time scales of less than a generation and when there is no obvious environmental driver, social learning (culture) may be operating (Rendell \& Whitehead 2001). While the calls of many marine mammals are known to vary, temporal and geographic variation is best known among the songs of male humpback whales Megaptera novaeangliae. At any one time, male humpbacks in a region sing nearly the same song, but the song changes noticeably over the breeding season and substantially over subsequent years (Payne \& McVay 1971, Payne et al. 1983). Cerchio (1993) suggests that the variation in humpback song can be likened to temporal dialects in which conformity may be socially significant, as in birds (Payne 1982). While humpback song was once thought to be a unique example among non-human animals of a continuously evolving conformist culture in a large and dispersed population (Payne 2000, Rendell \& Whitehead 2001), the worldwide coverage and time span of data on blue whales exceeds even that of humpback whales. Conformist cultures - in which individuals adopt the most common form of behavior present in the population - can lead to the structuring of a population into culturally marked groups (Boyd \& Richerson 1985, Whitehead 2008). While it is unclear why cultural conformity would drive blue whale song frequencies lower, it is clear that all regions in the world are experiencing the same direction of change. This leads to the question, without resolution, of whether there are cultural linkages among blue whale populations worldwide.

\section{Sexual selection}

Blue whales are widely dispersed during the breeding season, and while it is reasonable to assume that songs function to advertise the species and location of the singing whale, it is not known to what extent blue whale song is also under selection as a form of inter- and/or intra-sexual display. In many terrestrial species with acoustic displays, such as birds, anurans and insects, sexual selection is known to favor males whose calls are correlated with large body size, or those mates that sing longer or more complex songs (Rand \& Ryan 1981, Searcy \& Andersson 1986, Catchpole \& Slater 1995, Searcy
1996, Gerhardt \& Huber 2002). Over evolutionary time scales, sexual selection is also known to cause directional selection in male traits (Ryan et al. 1990, Andersson 1994). In blue whales (the largest animal on the planet), an honest indicator of large body size as indicated by a male's ability to sing songs of a lower pitch at a greater amplitude may be favored in mate selection by females or in competition with other males. Sexual selection for low frequency song may explain in part the frequency shift in blue whale song. Ascertaining which characteristics of blue whale song may be used to locate and assess singers is by no means straightforward and is complicated by associated trade-offs in short-distance and longdistance communication (as explained below and in Supplement 3 available at: www.int-res.com/articles/ suppl/n009p013_app.pdf). In addition, the culture of song synchrony makes it difficult to identify the variation upon which selection might act. Future work to examine the relative complexity of blue whale songs among geographic regions may provide additional insights into the differences in the intensity of selection and density of individuals among regions, as predicted by studies of birds (Catchpole 1980, Kroodsma 1983, Price 1998).

\section{Increase in body size post whaling}

With the cessation of commercial whaling, it is reasonable to assume that the size of blue whales has increased over time, raising the question of whether this could drive the observed frequency shift. However, the corresponding increases in lung and vocal tract volume over the past $40 \mathrm{yr}$ are at most a secondary factor in explaining the frequency shift. During the whaling era, large animals were selectively removed from populations, both because of whaling regulations limiting the catch to large animals (>21.3 $\mathrm{m}$ for North Pacific blue whales), and because of the economic value of large animals. Indeed, whaling data for the northeast Pacific suggest a reduced body length for blue whales harvested from 1960 to 1965, the final decade of whaling (Gregr et al. 2000). Following the cessation of whaling, body size would be expected to return to the pre-whaling distribution due to the removal of hunting pressure on mature animals. Since blue whales reach sexual maturity and have $95 \%$ of their mature body weight at 8 yr (Lockyer 1978), it seems likely that body size distributions have returned to near pre-whaling values in much less than the $40 \mathrm{yr}$ since the cessation of whaling. The continued linear shift in pitch and calculations relative to lung volume changes suggest this is not a primary factor in the observations presented here. 


\section{Global climate change and ocean acidification}

Could changes in the sound transmission properties of the ocean be driving the shift? It is recognized that average global temperatures are increasing, causing higher average sound velocities in the uppermost ocean inhabited by blue whales (Levitus et al. 2005). However, the average warming of the ocean's uppermost $700 \mathrm{~m}$ over the last $40 \mathrm{yr}$ is estimated to be $0.1^{\circ} \mathrm{C}$ (Bindoff et al. 2007), or equivalently $0.3 \mathrm{~m} \mathrm{~s}^{-1}$ sound velocity increase in the mid-latitude Pacific. As a percentage of average surface sound velocity $(\sim 1500 \mathrm{~m}$ $\mathrm{s}^{-1}$ ), these changes are small, less than $0.02 \%$, compared to the $32 \%$ change in blue whale tonal frequencies. It is not clear how or why the whale sound generation source would change in concert with changes in the sound transmission properties of the ocean.

Acidification of the oceans with climate change is predicted to result in better sound propagation via a lowering of the acoustic absorption coefficient (Hester et al. 2008). At reasonable ranges for whale communications (up to several hundred $\mathrm{km}$ ), acoustic absorption is a small component of propagation losses, and the predicted changes appear small relative to a $32 \%$ shift in blue whale frequency. The potentially more significant impact of a decrease in sound absorption would be increased ocean ambient noise (see 'Anthropogenic noise' below).

\section{Biological interference}

Interactions between blue whales and other marine mammals may be another factor affecting call frequency. The other species which commonly produces substantial sounds in the blue whale frequency band is the fin whale. Fin whales use short $(<1 \mathrm{~s})$ pulsed calls. When blue and fin whales are producing songs or calls in close proximity, interference between their respective calls may encourage the blue whales to change the fundamental frequency of their calls to avoid overlap with the frequency band of the fin whale calls. Fin whale calls and songs, however, change seasonally and/or geographically, and blue whale songs occur above, below and within the fin whale frequency bands (McDonald et al. 2008), so it is unclear how this hypothesis would cause the blue whale songs to all shift down in frequency.

\section{Anthropogenic noise}

Blue whales may modify their call frequencies to adapt to increasing anthropogenic noise. The dominant low frequency noise in the deep-water northeast
Pacific is due to commercial shipping traffic, which occurs primarily in the same 10 to $100 \mathrm{~Hz}$ frequency band as blue whale songs. In the northeast Pacific, an approximate $12 \mathrm{~dB}$ increase in ambient noise is reported for the past 4 decades (Andrew et al. 2002, McDonald et al. 2006b). The shipping noise increase is likely less in the Antarctic where shipping traffic and noise levels are low and is likely greater in the northern Indian Ocean where shipping traffic and noise levels are high (Wagstaff \& Aitkenhead 1979, Širovic et al. 2009).

A lowered fundamental frequency in the band near $20 \mathrm{~Hz}$ would not significantly lower the intrinsic attenuation of these acoustic signals, as spreading loss far outweighs signal attenuation at all practical propagation distances (e.g. 0 to $1000 \mathrm{~km}$ ). Likewise, a change of a few $\mathrm{Hz}$ would not substantially shift the blue whale signal relative to ambient noise (McDonald et al. 2006b). A lowered fundamental call frequency is predicted to result in lower blue whale call source levels (see Supplement 3), counter to the expectation that call source levels would increase to compensate for increased noise. The frequency shift plot looks nearly linear in frequency and time. This is not the relationship to be expected if the animals were shifting away from a linear increase in ambient noise, as it becomes exponentially more difficult to physiologically shift down $1 \mathrm{~Hz}$ as the frequencies become lower (Eq. S1). A quantitative assessment of the likely non-linear increase in sound source level to compensate for increased masking noise is a complex topic (Gelfand 2004). While ambient noise increase in the world's oceans may be an important factor, it appears not to be the dominant factor, as the expected frequency shift owing to increasing noise would be up rather than down.

\section{Population recovery from whaling}

Increasing population size is hypothesized to favor a decrease in song frequency (pitch) while still allowing effective communication with conspecifics. This hypothesis can be divided into 4 parts, the first being that there exists a trade-off between song frequency and sound amplitude as derived in Supplement 3 based on the physics of sound production. Physical acoustics argues that a higher song frequency corresponds to potentially higher amplitude (louder) songs and greater acoustic propagation distance. The blue whale call source level is argued to be limited by lung volume and vocal tract efficiency, thus a lower song frequency corresponds to potentially lower amplitude (perceived as quieter) songs and a decreased range at which these calls can be detected by conspecifics. As more source level measurements become available 
from more song types, the song amplitude versus song frequency relationship can be tested.

The second part of this hypothesis is the assumption that changes in population density can be sensed by the animals. One possibility is that population density would be acoustically sensed in terms of the number of other singers the whales hear, allowing males to change their song in response.

The third part of the hypothesis is that changing demographics are altering the sexually selected tradeoff for singing males between song source level (the ability to be heard at a greater distance) and song frequency (the ability to produce songs of lower pitch). Our records of blue whale song begin coincident with the end of commercial whaling, when population densities were dramatically reduced in many parts of the world. Male blue whales that lived in areas with low population densities at the end of the commercial whaling period may have needed to sing higher frequency and correspondingly louder songs to adequately communicate in some form of mate competition. During recovery, increasing population density has two possible influences on singing males. First, more males are singing, which potentially increases the intensity of sexual selection and may be causing the frequency of song to drop, as a lower frequency call may be preferred by sexual selection (see previous section on 'Sexual selection'). Second, there are more whales (both males and females) present, which potentially decreases the intensity of selection on males for long-distance communications, and thus the whales can afford to shift to lower frequencies in spite of correspondingly lower source levels.

The fourth and most speculative part of this hypothesis is that the distance a song can be heard can be related to population density. If true, the relative densities of blue whale populations, and the change in population density with time, can be theoretically calculated (Table 1). These results are likely confounded by changing ocean ambient noise in ways that are not yet understood. Nonetheless, the relative density and source level calculations in Table 1 appear to coincide with what is known of source level and density differences for whales of each song type (see further discussion in Supplement 2).

\section{CONCLUSIONS}

The demonstrated global trend in blue whale song frequency shift begs explanation. Changing demographics herald changes in the density of whales and the intensity of sexual selection. Coupled with a strong cultural component, we suggest that shifts in song frequency may be related to changes in a density index as these populations recover from commercial whaling, modified by global increases in ambient noise owing to shipping, and trade-offs between short-distance and long-distance communication. Blue whale song frequencies cannot continue to shift downward indefinitely and we suggest that song frequencies will stabilize as the population densities become stable.

\section{LITERATURE CITED}

Andersson M (1994) Sexual selection. Princeton University Press, Princeton, NJ

- Andrew RK, Howe BM, Mercer JA, Dzieciuch MA (2002) Ocean ambient sound: comparing the 1960's with the 1990 's for a receiver off the California coast. Acoust Res Lett Online 3:65-70

Aroyan JL, McDonald MA, Webb SC, Hildebrand JA, Clark D, Reidenberg JS, Laitman JT (2000) Acoustic models of sound production and propagation. In: Au WWL, Popper AN, Fay RR (eds) Hearing by whales and dolphins. Springer handbook of auditory research, Vol 12. Springer, New York, p 409-469

Bindoff NL, Willebrand J, Artale V, Cazenave A and others (2007) Observations: oceanic climate change and sea level. In: Solomon S, Qin D, Manning M, Chen Z and others (eds) Climate change 2007: the physical science basis. Contribution of Working Group I to the Fourth Assessment Report of the Intergovernmental Panel on Climate Change. Cambridge University Press, Cambridge

Boyd R, Richerson P (1985) Culture and the evolutionary process. University of Chicago Press, Chicago, IL

Branch TA, Matsuoka K, Miyashita T (2004) Evidence for increases in Antarctic blue whales based on Bayesian modeling. Mar Mamm Sci 20:726-754

Branch TA, Stafford KM, Palacios DM, Allison C and others (2007) Past and present distribution, densities and movements of blue whales Balaenoptera musculus in the Southern Hemisphere and northern Indian Ocean. Mammal Rev 37:116-175

Burtenshaw JC, Oleson EM, Hildebrand JA, McDonald MA, Andrew RK, Howe BM, Mercer JA (2004) Acoustic and satellite remote sensing of blue whale seasonality and habitat in the Northeast Pacific. Deep-Sea Res II 51: 967-986

Calambokidis J, Barlow J (2004) Abundance of blue and humpback whales in the eastern North Pacific estimated by capture-recapture and line-transect methods. Mar Mamm Sci 20:63-85

> Catchpole CK (1980) Sexual selection and the evolution of complex songs among European warblers of the genus Acrocephalus. Behaviour 74:149-166

Catchpole CK, Slater PJB (1995) Bird song: biological themes and variations, Cambridge University Press, Cambridge

Cerchio S (1993) Geographic variation and cultural evolution in songs of humpback whales (Megaptera novaeangliae) in the Eastern North Pacific. MSc thesis, Moss Landing Marine Laboratories, San Jose State University, San Jose, CA

Clapham PJ, Young SB, Brownell RL Jr (1999) Baleen whales: conservation issues and the status of the most endangered populations. Mammal Rev 29:35-60

Darling JD, Jones ME, Nicklin CF (2006) Humpack whale songs: Do they organize males on the breeding grounds? Behaviour 143:1051-1101 
Edds PL (1982) Vocalizations of the blue whale, Balaenoptera musculus, in the St. Lawrence River. J Mammal 63: 345-347

Gelfand SA (2004) Hearing - an introduction to psychological and physiological Acoustics, 4th edn. Marcel Dekker, New York, p 31-345

Gerhardt HC, Huber F (2002) Acoustic communication in insects and anurans. University of Chicago Press, Chicago, IL

Gregr EJ, Nichol L, Ford JKB, Ellis G, Trites AW (2000) Migration and population structure of Northeastern Pacific whales off coastal British Columbia: an analysis of commercial whaling records from 1908-1967. Mar Mamm Sci 16:699-727

Hester KC, Peltzer ET, Kirkwood WJ, Brewer PG (2008) Unanticipated consequences of ocean acidification: a noisier ocean at lower pH. Geophys Res Lett 35:L19601

Kroodsma DE (1983) The ecology of avian vocal learning. Bioscience 33:165-171

LeDuc RG, Dizon AE, Goto M, Pastene LA and others (2007) Patterns of genetic variation in Southern Hemisphere blue whales and the use of assignment test to detect mixing on the feeding grounds. J Cetacean Res Manag 9:73-80

Levitus S, Antonov JI, Boyer TP (2005) Warming of the world ocean, 1955-2003. Geophys Res Lett 32:L02604

Lockyer C (1981) Growth and energy budgets of large baleen whales from the southern hemisphere. In: Mammals in the seas, Vol 3. General Papers. Large cetaceans: FAO Fisheries Series (5), FAO Advisory Committee on Marine Resources Research, Working Party on Marine Mammals. Selected papers of the Scientific Consultation on the conservation and management of marine mammals and their environment, Bergen, 1976. Food \& Agricultural Organization of the United Nations, Rome, p 379-502

McDonald MA, Mesnick SL, Hildebrand JA (2006a) Biogeographic characterisation of blue whale song worldwide: using song to identify populations. J Cetacean Res Manag 8:55-65

McDonald MA, Hildebrand JA, Wiggins SM (2006b) Increases in deep ocean ambient noise in the Northeast Pacific west of San Nicolas Island, California. J Acoust Soc Am 120:711-718

McDonald MA, Hildebrand JA, Wiggins SM (2008) A 50 year comparison of ambient ocean noise near San Clemente Island: a bathymetrically complex coastal region off Southern California. J Acoust Soc Am 124:1985-1992

> Mellinger DK, Clark CW (2003) Blue whale (Balaenoptera musculus) sounds from the North Atlantic. J Acoust Soc Am 114:1108-1119

Mellinger DK, Stafford KM, Moore SE, Dziak RP, Matsumoto $\mathrm{H}$ (2007) An overview of fixed passive acoustic observation methods for cetaceans. Oceanography (Wash DC) 20: 36-45

Oleson EM, Calambokidis J, Burgess WC, McDonald MA, LeDuc CA, Hildebrand JA (2007) Behavioral context of call production by eastern North Pacific blue whales. Mar Ecol Prog Ser 330:269-284

Editorial responsibility: Andy Read, Beaufort, North Carolina, USA
Payne RB (1982) Ecological consequences of song matching: breeding success and intraspecific song mimicry in indigo buntings. Z Tierpsychol 70:1-44

Payne K (2000) The progressively changing songs of humpback whales: a window on the creative process in a wild animal. In: Wallin NL, Merker B, Brown S (eds) The origins of music. MIT Press, Cambridge, MA p 135-150

Payne RS, McVay S (1971) Songs of the humpback whales. Science 173:585-597

Payne K, Tyack PL, Payne R (1983) Progressive changes in the songs of humpback whales (Megaptera novaeangliae): a detailed analysis of two seasons in Hawaii. In: Payne R (ed) Communication and behavior of whales. Westview, Boulder, CO p 9-57

Price JJ (1998) Family and sex-specific vocal traditions in a cooperatively breeding songbird. Proc R Soc Lond B Biol Sci 265:497-502

Rand AS, Ryan MJ (1981) The adaptive significance of a complex vocal repertoire in a neotropical frog Physalaemus pustulosus. Z Tierpsychol 57:209-214

Reeves RR, Clapham PJ, Brownell RL, Silber GK (1998) Recovery plan for the blue whale (Balaenoptera musculus). National Marine Fisheries Service, Silver Spring MD

Reilly SB, Bannister JL, Best PB, Brown M and others (2009) Balaenoptera musculus. In: IUCN Red List of threatened species. www.iucnredlist.org/details/2477/0

> Rendell L, Whitehead H (2001) Culture in whales and dolphins. Behav Brain Sci 24:309-324

Ryan MJ, Fox JH, Wilczynski W, Rand AS (1990) Sexual selection for sensory exploitation in the frog Physalaemus pustulosus. Nature 343:66-67

Samaran F, Adam O, Motcsh JF, Guinet C (2008) Definition of the Antarctic and pygmy blue whale call templates. Application to fast automatic detection. Can Acoust 36:93-102

Searcy WA (1996) Sound-pressure levels and song preferences in female red-winged blackbirds (Aegelaius phoeniceus) (Aves, Emberizidae). Ethology 102:187-196

Searcy WA, Andersson M (1986) Sexual selection and the evolution of song. Annu Rev Ecol Syst 17:507-533

Širovic A, Hildebrand JA, Wiggins SM, McDonald MA, Moore SM, Thiele D (2004) Seasonality of blue and fin whale calls west of the Antarctic Peninsula. Deep-Sea Res II 51:2327-2344

Širovic A, Hildebrand JA, Wiggins SM, Thiele D (2009) Blue and fin whale acoustic presence around Antarctica during 2003 and 2004. Mar Mamm Sci 25:125-136

- Stafford KM, Nieukirk SL, Fox CG (1999) An acoustic link between blue whales in the Eastern Tropical Pacific and the Northeast Pacific. Mar Mamm Sci 15:1258-1268

Wagstaff RA, Aitkenhead JW (1979) Ambient noise measurements in the northwest Indian Ocean. US Navy Journal of Underwater Acoustics, reprinted in IEEE Journal of Oceanic Engineering (2005) 30:295-302

Whitehead H (2008) Social and cultural evolution in the ocean: convergences and contrasts with terrestrial systems. In: Conway Morris S (ed) The deep structure of biology. Templeton Foundation Press, West Conshohocken, PA, p 143-160

Submitted: October 23, 2008; Accepted: June 19, 2009

Proofs received from author(s): October 15, 2009 